\title{
DISCURSOS SUSTENTÁVEIS PARA POLÍTICAS PÚBLICAS INSUSTENTÁVEIS
}

\author{
Maria Fiszon ${ }^{1}$ \\ Liebert Rodrigues ${ }^{2}$
}

\begin{abstract}
RESUMO
O presente artigo estuda o uso do discurso ambiental na legitimação de políticas públicas de remoção e cercamento de favelas na cidade do Rio de Janeiro. Esse discurso, enunciado pelas autoridades e veículos midiáticos, se apoia em argumentos nos quais a defesa da natureza justifica ações urbanas, que acentuam o quadro de exclusão vivido pelos moradores das favelas. A partir de uma abordagem teórica crítica discute-se o uso do termo sustentabilidade como reforço positivo para as mais diferentes práticas, por seu caráter aparentemente neutro, em nome de um pretenso bem comum. Assim, a análise avança sobre a denominação "áreas de risco", utilizada amplamente após as chuvas ocorridas em abril de 2010, no Rio de Janeiro, para validar quaisquer remoções em localidades favelizadas, ainda que muitas destas não estivessem situadas em terrenos geologicamente instáveis. Os primeiros resultados apontam que o discurso das "áreas de risco" faz parte de um repertório de argumentos que se utilizam da consciência ambiental para legitimar ações de remoção e contenção de áreas de baixa renda, enquanto que as áreas de alto padrão em sítios semelhantes aos considerados "de risco" permanecem intactas. Tendo em vista tal contradição, é possível conjecturar que este apelo discursivo, dito sustentável, naturaliza políticas públicas segregadoras, que negam à população em situação favelada o direito à cidade.
\end{abstract}

PALAVRAS-CHAVE: Discurso ambiental, favela, áreas de risco.

\section{HOW SUSTAINABILITY DISCOURSE IS USED TO SUPPORT UNSUSTAINABLE PUBLIC POLICIES}

\begin{abstract}
The following article brings a study on how the environmental protection discourse is used to authorize urban public policies in favelas in Rio de Janeiro, which includes the removal and enclosure of the favelas. The discourse, given by the media and the government, uses arguments about nature's preservation to justify the exclusion process that favela's inhabitants are often submitted. From a

\footnotetext{
${ }^{1}$ Mestre em Arquitetura e Urbanismo, Programa de Pós-Graduação em Arquitetura e Urbanismo Universidade Federal Fluminense. mariafiszon@gmail.com

${ }^{2}$ Mestrando em Geografia, Programa de Pós-Graduação em Geografia-Universidade do Estado do Rio de Janeiro. liebertrodrigues@gmail.com.
} 

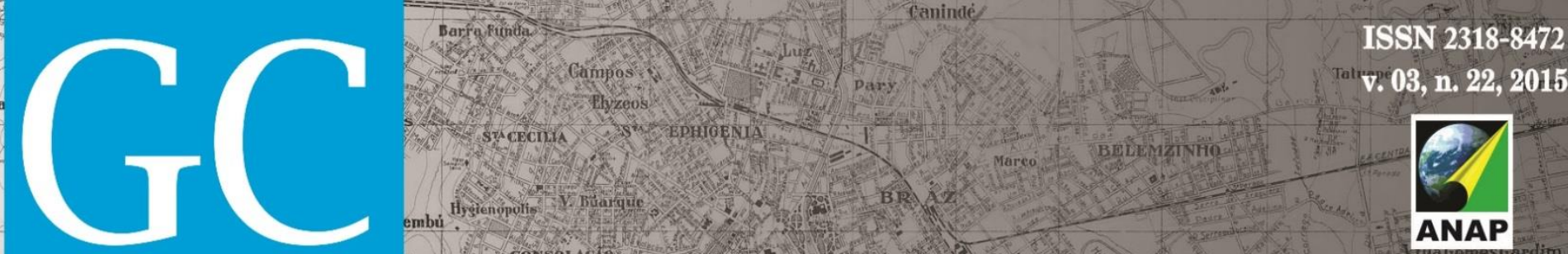

Revista Nacional de

Gerenciamento de Cidades

critical approach, the discussion follows questioning the acceptance of sustainability as a term that always attaches beneficial aspects supposedly above political and economic interests. Therefore, the analysis discuss how the denomination of "risk areas", is a meaning to validate different removal actions in favelas, especially after the historical storms that took place in April 2010, even if they are not all located in areas under collapse risk. First results indicate that the "risk areas" discourse is part of repertory of arguments that use environmental responsibility to legitimate remove and contain areas occupied by low-income population, while high-income areas that occupy locations with similar geological conditions rest untouched. Observing these aspects, is possible to evaluate that the environmental approach, introduced as sustainable, give to segregating public policies a higher acceptance, denying to favela's inhabitants democratic access to the city.

KEYWORDS: Environmental discourse, favela, risk areas.

\section{DISCURSOS SOSTENIBLES PARA POLÍTICAS PÚBLICAS NON SOSTENIBLES}

\section{RESUMEN}

El presente artículo presenta un estudio el uso del discurso ambiental en la legitimación de políticas públicas de remoción y cercamiento de favelas en la ciudad de Rio de Janeiro. Este discurso, enunciado por las autoridades y los medios de comunicación, se basa en argumentos en los cuales la defensa de la naturaleza justifica acciones urbanas, que agravan el escenario de exclusión vivido por los habitantes de las favelas. Desde un abordaje teórico crítico se discute el uso del término sustentabilidad como refuerzo positivo para las más diferentes prácticas, por su carácter aparentemente neutral, en nombre de un supuesto bien común. Por lo tanto, el análisis avanza acerca de la denominación "áreas de riesgo", utilizada ampliamente tras las lluvias, que ocurrieron en abril del 2010 para validar remociones cualesquiera en las localidades de las favelas, aunque muchas de estas no estuvieran situadas en terrenos geológicamente instables. Los primeros resultados señalan que el discurso de las "áreas de riesgo" es parte de un repertorio de argumentos que se utilizan de la consecuencia ambiental para legitimar acciones de remoción y contención de zonas de bajos ingresos, mientras que las zonas de más alto prestigio en sitios semejantes a los considerados "de riesgo" permanecen intactas. Considerando tal contradicción, es posible conjeturar que esta apelación discursiva, dicha sostenible, naturaliza las políticas públicas segregativas, que niegan a la población en situación marginal el derecho a la ciudad.

PALABRAS CLAVE: Discurso ambiental, favela, áreas de riesgo.

\section{INTRODUÇÃO}

Os movimentos ambientais tiveram início há mais de dois séculos, sendo difícil precisar o momento em que surgem. Pode-se dizer que em meados do século XX a temática da preservação ambiental ganha amplitude, trazendo a compreensão 
$\mathrm{T}$

Revista Nacional de

Gerenciamento de Cidades

de que a natureza, ao contrário do que se acreditava, não é capaz de absorver infinitamente a degradação gerada pelas intervenções humanas.

Nesse período, principalmente a partir dos anos 1960, as preocupações ambientais passam a ser entendidas como um problema a ser enfrentado pela humanidade como um todo, com o tema alcançando grande relevância perante a opinião pública (FISZON, 2015). A natureza mostra-se frágil, por sua existência aparentemente estática, sem possibilidades de defesa diante do maquinário humano que constrói as cidades e urbaniza o mundo.

De fato, a segunda metade do século $X X$ assiste ao desenvolvimento do capitalismo e, com ele, a novos surtos de urbanização (IANNI, 1997), com a população mundial tornando-se majoritariamente urbana em 2007 (ONU-Habitat, 2011). A nova urbanização generaliza padrões de vida social e cultural urbanos, produzindo novos espaços e relações.

São perceptíveis as consequências desse processo, que vão desde mudanças climáticas e impactos ambientais, até crises na distribuição de alimentos, energia e água, na saúde, no mercado financeiro e na economia. A cidade se apresenta como um desafio e, especialmente, como local da busca por soluções para os problemas que gera (BETTENCOURT \& WEST, 2010).

Todavia, esse surto de urbanização não resulta de uma busca por atender às necessidades das populações. $O$ crescimento desenfreado das cidades envolve estratégias que absorvem o capital excedente usando o mercado da construção civil. O lucro sobre valores de troca é maximizado, independente das demandas por valores de uso, ou seja, sem atender as reais necessidades urbanas (HARVEY, 2015). Como consequência revela-se um modelo de urbanização extremamente irracional, no qual as atividades econômicas exploram recursos naturais de forma nunca antes vista, sem contemplar a face humana do meio urbano. Para essa urbanização, que constitui um sítio infindável de acumulação de capital, populações inteiras podem ser atingidas de forma violenta em nome do lucro. 
A qualidade ambiental das cidades passa a ser, cada vez mais, um privilégio de poucos, sendo notória a forma desigual com que os problemas ambientais urbanos atingem diferentes camadas da população (FISZON, 2015). Evidentemente, o nível da precariedade socioambiental que resulta disso é muito mais alto dentre as populações mais pobres, já que habitam áreas menos protegidas e, portanto, mais sujeitas aos agravos ambientais (JACOBI, 1997). A exclusão, no entanto, irá ocorrer não apenas no acesso aos espaços "verdes", mas também nas próprias justificativas do discurso da preservação ambiental.

A cidade desigual é também problematizada por movimentos de justiça ambiental e de denúncia de racismo ambiental (...) em defesa do igual acesso à proteção ambiental e aos recursos urbanos como direito de todos os citadinos, seja em termos de nível de renda ou de origem étnica. Movimentos contra a ambientalização da exclusão denunciam a evocação de argumentos ambientais para legitimar remoções de populações faveladas que, por sua vez, nunca foram atendidas em seu direito à moradia, dada a ausência histórica de políticas públicas habitacionais adequadas. (ACSELRAD, 2013, p. 243)

A defesa da natureza, em toda sua aparente fragilidade, é usada para validar ações que ocorrem dentro das cidades, tendo penetrado profundamente em toda a esfera da reprodução social contemporânea (LIMONAD, 2010). É aí que a sustentabilidade deriva como um termo de aparente neutralidade, usado como reforço positivo para as mais diversas propostas e práticas. Consensualmente, ser sustentável designa algo benéfico devendo ser almejado pela humanidade em nome de um pretenso bem comum (LIMONAD, 2013).

Intervenções urbanas articuladas a partir dessa argumentação se mostram mais facilmente aceitas, uma vez que são entendidas como parte da resposta à problemas que afetam a humanidade. "O esforço teórico que temos ainda que fazer é, neste contexto, o de tentar trazer essa discussão de sustentabilidade para o campo das relações sociais" (ACSELRAD, 2004, p. 4).

A discussão, portanto, não pode ficar restrita à sustentabilidade dos recursos e do meio ambiente, mas deve avançar sobre as formas de apropriação e uso 
Revista Nacional de

Gerenciamento de Cidades

destes recursos e deste ambiente. Observa-se, a partir do entendimento das lutas sociais presentes nas cidades, a disputa entre os diferentes modos de apropriação e uso da base material das sociedades (ACSELRAD, 2004, p. 4).

Nesse âmbito, este trabalho busca reunir estudos acerca dos discursos da sustentabilidade a pesquisas sobre políticas públicas de remoção de favelas. Concentra-se majoritariamente em ações perpetradas na cidade do Rio de Janeiro nos últimos anos, abrindo-se para futuros desdobramentos do tema.

\section{A JUSTIFICATIVA AMBIENTAL}

A vulnerabilidade do meio urbano às alterações climáticas e aos danos ecológicos é facilmente reconhecida, com seus efeitos sendo diretamente sentidos pela população. Os chamados eventos extremos acontecem em todo o mundo com danos socioambientais dramáticos, (ABRAMOVAY, 2010) com as cidades constantemente sujeitas a inundações, nevascas, desabamentos de construções e deslizamentos de encostas.

No contexto urbano brasileiro esses eventos são notórios com a maior frequência de enchentes, deslizamentos de encostas e desmoronamentos, que se tornam amplamente visíveis ao provocarem o bloqueio de vias de circulação e danos materiais. As crises no abastecimento de água e energia, dificuldades na gestão de resíduos sólidos e de despejo adequado do lixo são constantes, além dos efeitos sentidos na qualidade do ar e da água ao afetarem a saúde da população.

A cidade sente as repercussões desses efeitos, mas é inaceitável pensar que seus impactos são distribuídos de forma indistinta. São aqueles que habitam as áreas mais frágeis, em geral mais distantes dos centros e com menor acesso à infraestrutura, que sentem mais intensamente os resultados dos agravos ambientais.

Essa divisão resulta justamente do modelo de urbanização exploratório, no qual as populações excluídas do processo de acumulação capitalista não encontram possibilidade de participação na cidade formal. 


\section{Revista Nacional de}

Gerenciamento de Cidades

As áreas ambientalmente frágeis - beira de córregos, rios, e reservatórios, encostas íngremes, mangues, áreas alagáveis, fundos de vale - que, por essa condição, merecem legislação específica e não interessam ao mercado legal, são as que "sobram" para a moradia de grande parte da população. As consequências são muitas: poluição dos recursos hídricos e dos mananciais, banalização de mortes por desmoronamentos, enchentes, epidemias etc. (MARICATO, 2012, p. 163).

A ausência de políticas sociais e a regulação do espaço urbano por um mercado imobiliário excludente, fazem com que a invasão de terras urbanas no Brasil seja estrutural e institucionalizada, como ainda explica Maricato (2012). A falta de alternativas habitacionais torna inviáveis outras soluções, principalmente a partir dos anos 1950, com a intensificação do processo de urbanização.

O comprometimento ambiental gerado a partir dessa dinâmica urbana mostrase cada vez mais insustentável, gerando uma crise de legitimidade das próprias políticas urbanas, que se revelam incapazes de contornar os riscos presentes nas cidades. Como esclarece Acselrad (1999), há uma concepção culturalmente construída do risco, ou do que são áreas de risco, que transparece a desigualdade no acesso aos serviços urbanos. As áreas menos atendidas por investimentos públicos, serão, consequentemente, as mais afetadas pelos riscos causados pela imperícia técnica.

\section{O DISCURSO SOBRE AS ÁREAS DE RISCO}

Em mais de 100 anos, desde o surgimento da primeira favela no Rio de Janeiro, a ameaça de remoção é um fantasma presente no cotidiano dos moradores de áreas favelizadas. No contexto contemporâneo, esse fenômeno parece seguir uma lógica no reordenamento urbano experimentado pela cidade. A administração municipal de Eduardo Paes (2009-2016) ressuscitou a política da remoção de favelas, que foi notória durante os governos de Pereira Passos (1902-1906) e Carlos Lacerda (1961-1965). Foram removidas mais de 37 mil pessoas de suas casas, 


\section{Revista Nacional de}

sendo Paes o prefeito campeão de remoções, em números absolutos, se comparado as 31 mil de Lacerda e 20 mil de Passos (FAULHABER, 2012, p. 38) ${ }^{3}$.

Fênomeno recorrente em diferentes momentos do processo de urbanização do Rio de Janeiro, as remoções voltam a ser uma prática para uma suposta "valorização da cidade" (FAULHABER, 2012, p. 37), expondo a face da "limpeza urbana-humana" norteada pelas áreas de interesse imobiliário.

Ao longo do século $\mathrm{XX}$, diversas medidas higienistas foram executadas a partir da premissa da favela como sujeira na paisagem carioca, legitimando ações que incluem a expulsão de moradores e demolição de construções, como soluções urbanísticas e ambientais. (RODRIGUES, 2014)

Reportagens como a publicada pelo jornal O Globo intitulada "Remoções salvaram a paisagem da Lagoa - Cartão postal do Rio poderia ter sido transformado em complexo de favelas com pelo menos 96 mil moradores" (Figura 1), entendem a favela como um corpo estranho, um tumor que foi extirpado da paisagem da Lagoa, bairro nobre da cidade do Rio de Janeiro, graças às remoções.

\footnotetext{
${ }^{3}$ Segundo os dados do gráfico Número de pessoas removidas por gestão municipal, elaborado por Lucas Faulhaber, com dados coletados da SMH; ROCHA, 1995, p.69; LEEDS, 1978, p.220 in FAULHABER, 2012, p.38.
} 


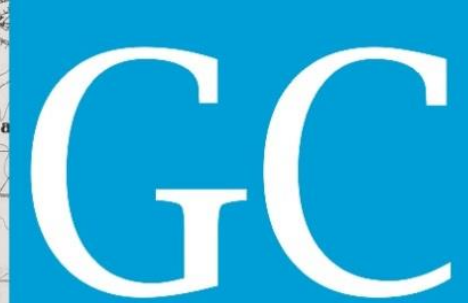

Revista Nacional de Gerenciamento de Cidades

Figura 1: Manchete e imagem de reportagem retiradas do jornal O Globo

\section{Remoções salvaram a paisagem da Lagoa}

Cartão postal do Rio poderia ter sido transformado em complexo de favelas com pelo menos 96 mil moradores

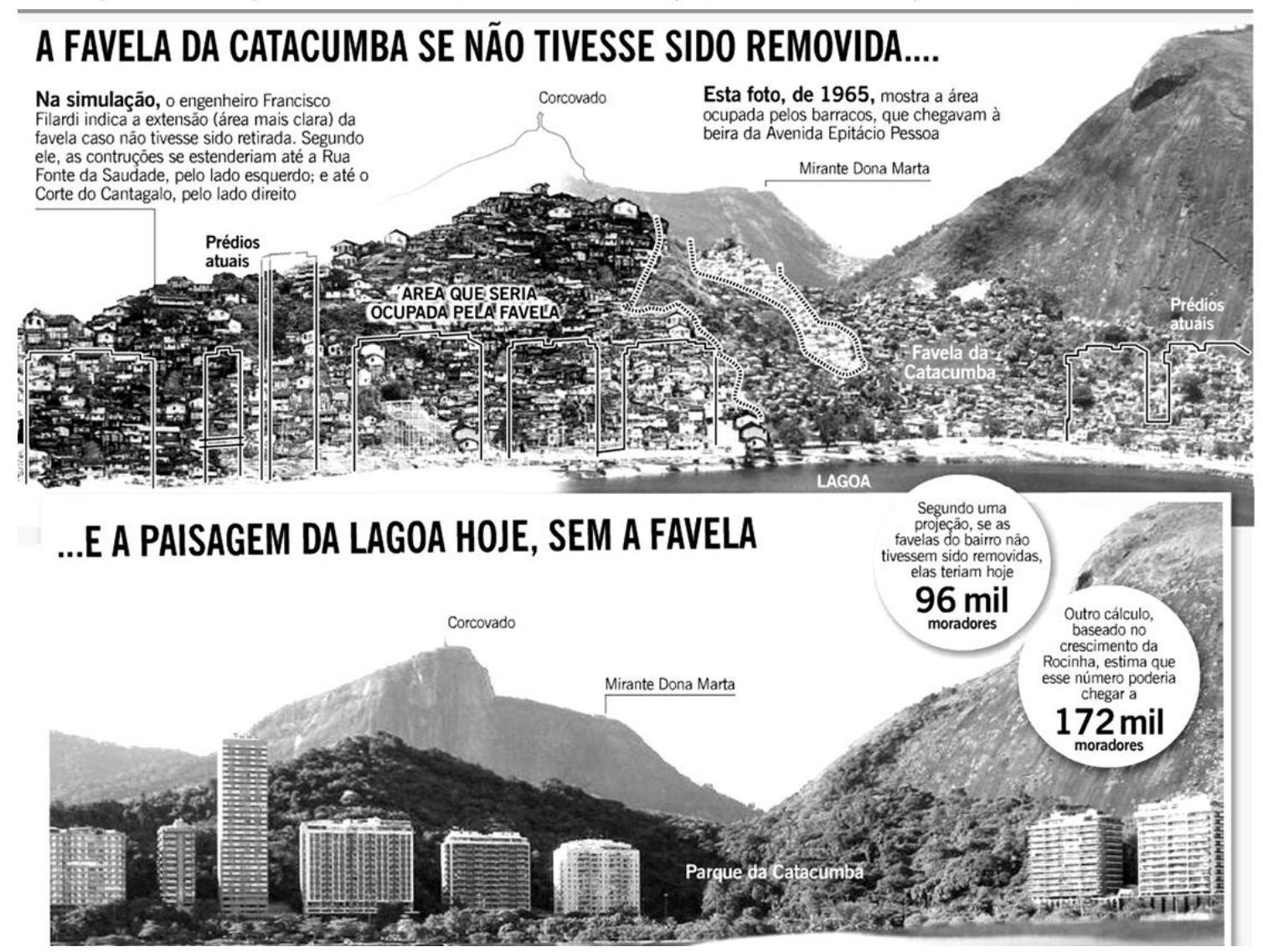

Fonte: O Globo 12 abril 2009, caderno Rio p. 15.

A simulação ilustrativa e o discurso jornalístico da referida matéria sugerem a favela como um corpo estranho a ser eliminado da paisagem carioca; um elemento desagradável que insiste em assediar as belezas da Cidade Maravilhosa. A preocupação estética manifestada pelo jornal $O$ Globo ignora a injustiça e a brutalidade acerca da remoção da Favela da Catacumba ${ }^{4}$, e a subsequente realocação dos antigos moradores do local para a Cidade de Deus.

\footnotetext{
${ }^{4} \mathrm{O}$ terreno onde nasceu a Favela da Catacumba pertencia à Baronesa da Lagoa Rodrigo de Freitas, que transferiu, no início do século $\mathrm{XX}$, a posse destas terras para os seus ex-escravos. $\mathrm{O}$ assentamento que ali surgiu deu origem, aos primeiros barracos que constituiriam a extinta favela. $\mathrm{A}$
} 
Eduardo Paes mostra sua posição favorável às remoções de favelas em sua administração. Sua declaração ao O Globo na reportagem "Rio vai remover 119 favelas de áreas de risco em 2 anos" (Figura 2), deixa claro seu pensamento nesse sentido, ao determinar: "Tem que acabar com a demagogia e retirar. Não vamos fazer obras de milhões para segurar algumas casas" (O Globo, 2010a). Na mesma matéria, o referido jornal expressa a opinião editorial: "Desmistifica-se, afinal, o termo 'remoção', para o bem de todos os cariocas" (O Globo, 2010a).

Figura 2: Manchete de reportagem retirada do jornal O Globo

\section{Rio vai remover 119 favelas de áreas de risco em 2 anos}

Secretário de Segurança anuncia criação de UPPs na Rocinha e no Vidigal

Fonte: O Globo 01 jan. 2010 p. 1.

Em 2010 desastres decorrentes das chuvas de abril tornaram oportuno o argumento das "áreas de risco" dentro da política de remoção de favelas. Essa argumentação justificou a retirada das edificações à 'toque de caixa', sem que houvesse uma prévia análise para distinção entre áreas com risco de deslizamento daquelas situadas em terrenos estáveis ou consolidados. A manchete "Rio faz remoção obrigatória em área de risco" (FOLHA DE SÃO PAULO, 2010) revela o caráter de urgência dado às operações de remoção.

posse do terreno por parte dos seus antigos moradores era legítima e, na década de 1970, sob o Regime Militar, o governo decidiu remover os moradores da Catacumba, substituindo a favela pelo Parque da Catacumba, que ocupa o local atualmente. 
Revista Nacional de Gerenciamento de Cidades

Figura 3: Manchete de reportagem retirada do jornal Folha de São Paulo

\section{Riofaz remoçãoobrigatória emárea de risco}

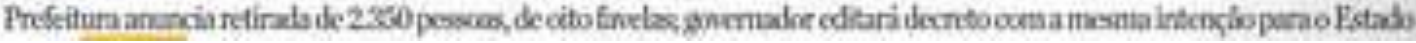

Fonte: Folha de São Paulo, caderno Cotidiano, C4 in FERRAZ, S., CARDOSO, N., RODRIGUES, L. Arquitetura da Violência: Cidade limpa e segura para turista ver. III Seminário Internacional de Derechos Humanos, Violencia y Pobreza. Montevidéu, 24/26 nov. 2010

Entretanto, os riscos relacionados ao deslizamento das encostas e à preservação ambiental não aparecem no discurso da prefeitura do município do Rio de Janeiro ao promover a abertura das encostas para o mercado imobiliário, como revela a matéria "Paes quer flexibilizar ocupação de encostas" (O GLOBO, 2010b).

Figura 4: Manchete e imagem de reportagem retiradas do jornal O Globo

\section{Paes quer flexibilizar ocupação de encostas}

Emenda ao Plano Diretor enviada pelo prefeito autoriza abertura de ruas em morros e abre caminho para construções

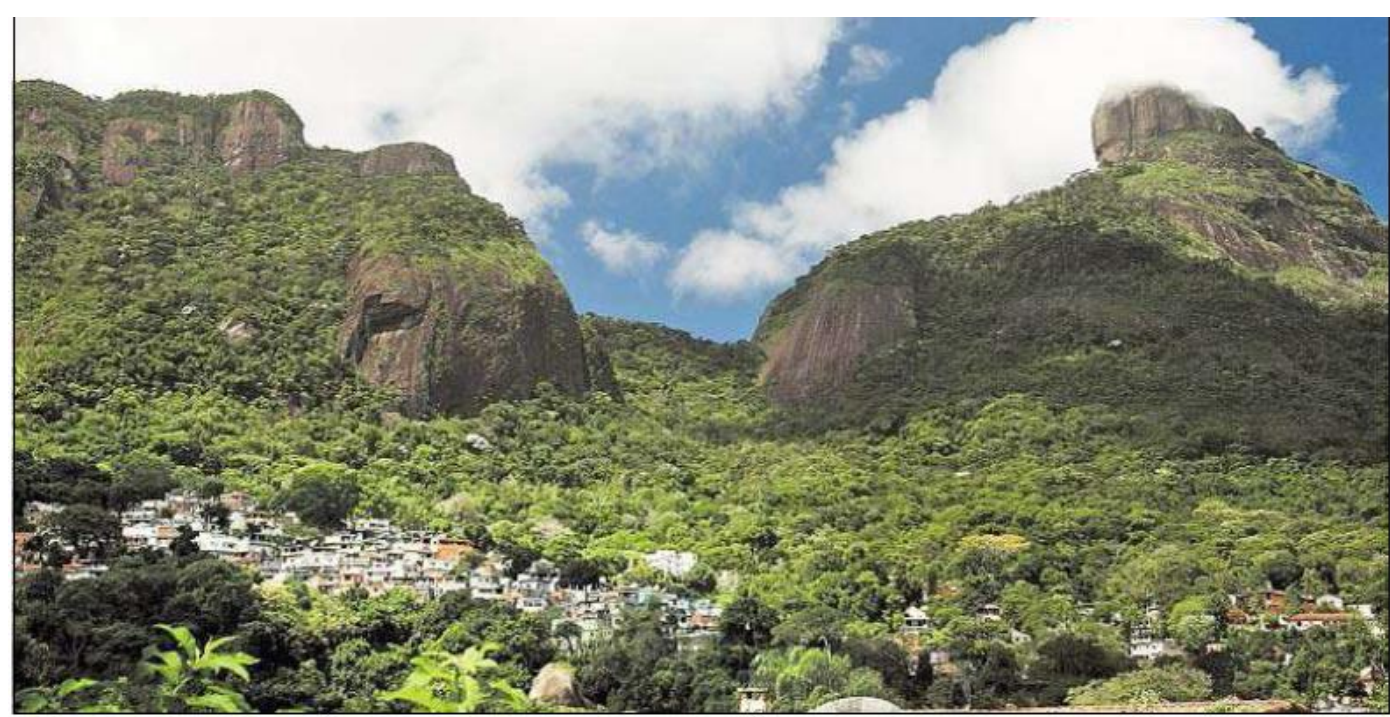

COMUNIDADE NO ITANHANGÁ: moradores da região cobram medidas do poder público para evitar o aumento da favelizaçảo na área

Fonte: O Globo 25 junho 2010, caderno Rio p. 21. 
Até que ponto conceitua-se área de risco com base no nível social de quem a ocupa o espaço urbano? A partir dessa constatação pode-se levantar a hipótese de que, mais do que o risco de desabamento, o problema da ocupação das encostas é o próprio surgimento de favelas. Ainda que muitas das casas não estejam localizadas em terrenos com risco de deslizamento, todas as edificações ameaçadas de remoção foram avaliadas no mesmo contexto das localidades implantadas em terrenos geologicamente instáveis.

\section{CONSIDERAÇÕES FINAIS}

O presente artigo se propôs a introduzir a questão dos discursos ambientais, emitidos pelas autoridades e veículos midiáticos, que legitimam políticas públicas onerosas para as favelas da cidade do Rio de Janeiro. Os primeiros resultados obtidos demonstram que o discurso das áreas de risco faz parte de um repertório de argumentos que se utilizam da consciência ambiental para legitimar ações de remoção e contenção de áreas de baixa renda, sendo então um veículo de naturalização de práticas que acentuam a desigualdade no direito à cidade. Ao mesmo tempo, este discurso não se articula da mesma forma quando se trata da manutenção e expansão de áreas residenciais de alto padrão em localidades semelhantes.

A partir desses argumentos, são perceptíveis as contradições nos discursos empreendidos tanto pela mídia quanto pelo governo. É possível conjecturar que este apelo, dito sustentável, naturaliza políticas públicas de segregação, que negam à população em situação favelada o direito à cidade.

Dentro deste mesmo argumento a construção de muros no perímetro das favelas cariocas localizadas em áreas nobres foi justificada pelo poder público a partir do discurso dos ecolimites, que se apresentaram como uma solução para a proteção da Mata Atlântica. Os enunciados relativos a este tema serão desdobrados 
Revista Nacional de Gerenciamento de Cidades

nas próximas etapas de pesquisa, da mesma forma que novos tópicos sobre as áreas de risco.

\section{REFERÊNCIAS BIBLIOGRÁFICAS}

ABRAMOVAY, R. Alimentos versus população: está ressurgindo o fantasma malthusiano? Ciência e Cultura, 62, pp. 38-43, 2010.

ACSELRAD, H.. Discursos da Sustentabilidade Urbana. Revista Brasileira de Estudos Regionais e Urbanos, v. 1, p. 79-90, 1999.

Sustentabilidade e articulação territorial do desenvolvimento brasileiro. II Seminário Internacional sobre Desenvolvimento Regional. Santa Cruz do Sul, 29 set./01 out. 2004.

. Cidade-Espaço Público? Revista UFMG, v.20, n.1, p. 234-247, jan./jun.2013. Disponível em:

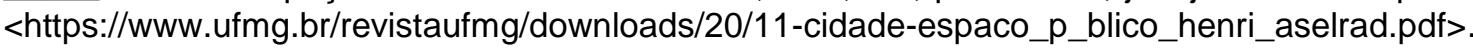

BETTENCOURT, L., \& WEST, G.. A unified theory of urban living. Nature, v.467 p. 912-913, 21 out. 2010.

FAULHABER, L: Rio Maravilha: práticas, projetos e intervenções no território. 2012. Trabalho Final de Graduação (Arquitetura e Urbanismo) - Escola de Arquitetura e Urbanismo, Universidade Federal Fluminense, Niterói, 2012.

FERRAZ, S., CARDOSO, N., RODRIGUES, L. Arquitetura da Violência: Cidade limpa e segura para turista ver. III Seminário Internacional de Derechos Humanos, Violencia y Pobreza. Montevidéu, 24/26 nov. 2010

FISZON, M. Certificações Ambientais e a Qualificação da Arquitetura: Razão de Ser ou Razão de Valer? 2015. Dissertação (Mestrado em Arquitetura e Urbanismo) - Programa de Pós Graduação em Arquitetura e Urbanismo, Universidade Federal Fluminense, Niterói, 2015.

HARVEY, D. A crise da urbanização planetária. A crise da urbanização planetária. Disponível em:: http://blogdaboitempo.com.br/2015/01/10/david-harvey-a-crise-da-urbanizacao-planetaria/. Acesso em : 29 mar 2015.

IANNI, O. A Cidade Global. In O. Ianni, A Era do globalismo, 3르 ed., p. 59-85. Rio de Janeiro: Civilização Brasileira, 1997.

JACOBI, P. Meio ambiente urbano e sustentabilidade: alguns elementos para reflexão. Em C. C. (org.), Meio ambiente, desenvolvimento sustentável e políticas públicas, p. 384-390. São Paulo: Cortez, 1997.

LIMONAD, E.. A natureza da "ambientalização" do discurso do planejamento. Scripta Nova, Barcelona, v XIV, n. 331, 1 ago. 2010. Disponível em: <http://www.ub.edu/geocrit/sn/sn-331/sn-33166.htm> 


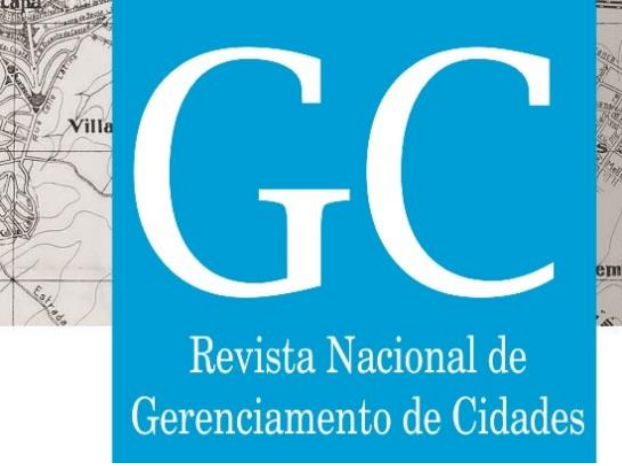

A insustentável natureza da sustentabilidade. Da ambientalização do planejamento às cidades sustentáveis. Cadernos Metrópole (PUCSP), São Paulo, v.15, n.29, p. 123-142, jan/jun 2013.

MARICATO, E. As ideias fora do lugar e o lugar fora das ideias. In O. B. ARANTES, C. VAINER, \& E. MARICATO, A cidade do pensamento único, $7^{\mathrm{a}}$ ed.. p. 121-188. Petrópolis: Vozes, 2012.

O GLOBO, Remoções salvaram a paisagem da Lagoa. O Globo, Rio de Janeiro, 12 abril 2009. Caderno Rio, p. 15.

O GLOBO, Paes quer flexibilizar ocupação de enconstas. O Globo, Rio de Janeiro, 25 junho 2010. Caderno Rio, p. 21.

O GLOBO, Rio vai remover 119 favelas de áreas de risco em 2 anos. O Globo, Rio de Janeiro, 01 jan. 2010. Primeiro Caderno, p. 1.

ONU-Habitat. (2011). Cities and climate change: global report on human settlements 2011. United Nations Human Settlements Programme. Londres/Washington, DC: UN Habitat/ Earthscan. Disponível em: http://unhabitat.org/books/cities-and-climate-change-global-report-on-humansettlements-2011/

RODRIGUES, L. Urbanismo do Apocalipse: favela carioca como um filme de ficção científica territórios da segregação e controle no cinema e na vida real. 2014. Trabalho Final de Graduação (Arquitetura e Urbanismo) - Escola de Arquitetura e Urbanismo, Universidade Federal Fluminense, 2014. 